Francisco Javier Ibisate

\title{
Lecciones y aplicaciones del Plan de nación
}

No es exagerado decir que el documento Bases para el plan de nación ha tenido un eco sonoro y una amplia audiencia a nivel de los departamentos nacionales. A los cinco meses de su publicación se siguen solicitando y dando charlas sobre su contenido, objetivos, temas concretos y sobre los valores humanos que se desean recomponer. En los últimos años, ninguno de los programas monelario-financieros del Banco Central de Reserva y del comité económico han gozado de similar aceptación y audiencia. Los tecnócratas del gobiemo quizás estén algo celosos y tienen sus motivos para preguntarse por la razón. Y es que el Plan de nación, que no es una hechura sino una encomienda del actual gobiemo, dice cosas concretas con palabras cercanas a la vivencia y las esperanzas de la mayoría de la población. El Plan de nación no dice que ya estamos bien sino que quisiéramos estar bien; no dice que nuestra economía es sana, fuerte y sostenible, o que somos un país condecorado verbalmente por instituciones internacionales. El Plan de nación dice que en los cinco ámbitos de la convivencia nacional queda un amplio abanico de problemas por resolver. $Y$ dice que se pueden resolver si hay una participación ciudadana, un aporte democrático que ayude a concretar ese elenco de problemas y a hacer propuestas de solución que sean escuchadas desde arriba.

El Plan de nación es una publicación para que el país entre en diálogo. Esto sí es un giro histórico o un cambio de agujas que lo debe tomar en cuenta el próximo gobierno. Como lo dijo el presidente el 1 de mayo y 1 de junio de 1997, era necesario un Plan de nación que nos dé una visión, a mediano y largo plazo, que genere estabilidad, confianza y continuidad. Estas palabras suenan como una autocrítica que el Plan de nación traduce en una propuesta crítica. Acostumbrados a cierto secretismo oficial, a la presencia clandestina de unos programas trienales del Banco Mundial (en inglés y top-secret), a medidas más sorpresivas que consultadas y a unos repetitivos cuadros y gráficos en la página 
económica de La Prensa Gráfica, el Plan de nación tiene el mérito de mostrar que hay otras realidades distintas de la realidad oficial.

El Plan de nación, incorporando análisis y propuestas de otras instituciones, dadas a luz desde 1993 y sobre todo en 1996-1997, nos acerca más a la verdad económica. Una de las víctimas de la guerra y postguerra ha sido la verdad en todos los órdenes, también en lo económico. Baste un pequeño ejemplo, por estar en la primera página del Plan de nación. "Desde nuestra perspectiva el desarrollo del país no puede reducirse al crecimiente de la economía El crecimiento es una condición necesaria pero no suficiente para lograr el desarrollo integral de El Salvador. Por ello concebimos el desarrollo como un proceso participativo que debe incluir de manera armónica factores económicos. territoriâles, ambientales, políticos, éticos, sociales y culturales". Por cierto que esta definición parece inspurarse en la matriz del "desarrollo multidimensional", comentado en la propuesta de FUNDE (p. 16...). Esta descripción del desarrollo nos acerca a una economía social pluridisciplinaria que desciende a la geografía ecologica, a la desintegración territorial, a la discusión de los modelos políticoecońómicos, a los valores éticos y a los derechos humanos. Son bases para una reflexión.

El análisis frío y repetitivo de los agregados superficiales de la macroeconomía nos había habituado a una ciencia económica desencarnada, monopolio de tecnócratas, donde el ser humano aparece como un posible beneficiario del "rebalse" productivo. Esta reflexión introductoria abre las puertas a los profesionales de los ámbitos mencionados para que den sus aportes científicos (con-ciencia), traduciendo en propuestas realistas las demandas y expectativas de la gran población. Las puertas están abiertas a todas las ideologías y partidos, y ofrecen una oportunidad para que los neoliberales hagan su autocrítica (Realidad, 1998; pp. 9-31).

También hay que decir que los autores del Plan de nación desearlan motivar un consenso general, a sabiendas de que hay de por medio discrepancias ideologicas o doctrinarias (p. 22). El reto es serio, no sólo porque se perciben las realidades desde prismas diferentes, sino porque en la presente década se quiere imponer un determinado modelo económico-político que, tanto a nivel mundial como nacional, se niega a hacer su autocrítica, pese a que los hechos históricos en nada confirman sus principios ideológicos. Algunos grupos e instituciones juzgan que la integración del "grupo gestor" puede ser un freno a la apertura abierta por el Plan de nacion. También existe la impresión de que en el último quinquenio hemos navegado entre el desconcierto y el retroceso, sumado ello a la desintegración global generada por el conficto civil. No nos será tan fácil llegar a un consenso nacional, pero sf podemos adelantar algunas lecciones y aplicaciones del Plan de nación. 
La intención del presente artículo es mostrar que estas discusiones, encuestas y propuestas de diálogo nacional no tienen como objetivo la sola revisión o valoración de nuestra economfa nacional, sino que buscan integrarse en un movimiento continental e incluso intercontinental; ir transcendiendo de Ta crítica y de la oposición a la cultura de la propuesta de alternativas posibles frente a la lógica mercantilista de la globalización. Si decimos o proponemos algo sobre nuestra situación nacional es con miras a irnos integrando a ese movimiento de una propuesta continental.

\section{El regreso de la planeación económica}

La traducción de un Plan de nación a la vida real requiere el regreso a las técnicas de planeación económica. Esta es una primera lección porque, en palabras del presidente, necesitamos tener una visión de mediano y largo plazo que genere estabilidad, confianza y continuidad. Como lo indica el Plan de nación y lo venían recomendando las propuestas económicas integradas en este Plan. necesitamos reestructurar el mecanismo.de funcionamiento de la econernía. No se trata, en manera alguna, de recomendar la institución de un Gosplan de la Unión y de las repúblicas, porque allá se confundió la planeación con la militarización de la economía (economía de ordeno y mando: Realidad, 1998; pp. 11-12), Se trata de una planeación dialogada, concertada, que encare la realidad. Una de las realidades señaladas en el Plan de nación es la creciente desintegración económica interna y externa, es decir, tanto la desintegración del mercado interno como la escasa capacidad competitiva para la integración en el mercado externo. Es necesario volver sobre este tema por la importancia que le concede el Plan de nación y la propuesta en que se basa ese documento.

Tampoco se trata de pronunciarse aquí por la reconstrucción de un Ministerio de Planificación tal cual, o por una Secretaría Adjunta al gobierno central. Por desgracia, existe un temor al querer hacer una recomendación concreta: que los técnicos ( $y$ hay buenos técnicos en el país) se vean supeditados u obligados a legitimar los criterios y políticas del partido de turno, cuando el cauce ordenado sería que el gobierno y partido de turno escuchen las propuestas de los entendidos. Se trataría, en cualquier caso, de una institución cercana pero independiente del gobierno central, capaz de dialogar con las dependencias de la administración pública, con los representantes empresariales y laborales de los sectores productivos, y que se acerque a recoger las demandas sociales populares.

Usamos la expresión de técnicos y no de tecnócratas porque con frecuencia éstos últimos son personas autosuficientes, muy preciados de si mismos y muy poco de los demás; en una palabra, son seres insoportables. Preferimos hablar de lécnicos porque el proceso de planeación económica, la visión del mediano y largo plazo requieren del manejo de múltiples técnicas. Y ojalá fueran los "técnicos de las bienaventuranzas", misericordiosos, de ojos limpios, con hambre y 
sed de justicia, con espíritu de pobreza (de hacer economías) porque somos un país de pobres y pobre en recursos. La planeación económica es la técnica de lograr los mayores resultados con los menores recursos.

\section{Una corta cronología}

En El Salvador nos iniciamos en la articulación de planes de desarrollo en la década de los sesenta, al mismo tiempo que se recopilaban los datos de nuestra contabilidad nacional. Esta onda nos llegaba, sin duda, desde el modelo de planificación indicativa o economía concertada de Europa occidental. Recordamos nuestro Conaplan y merece especial mención el Plan de Desarrollo Económico y Social, 1973-19977, por su filosofía sobre la función del Estado, sus propuestas de reformas estructurales y su entorno de escenarios alternativos. Pero las fuertes resistencias de los poderes económicos e ideológicos frustraron los lineamientos del plan, lección nunca aprendida: el crecimiento real de la década llegó al 5 por ciento, que en nada corrigió la desigualdad económica ni la marginación social. Así lo reconocí la proclama de los jóvenes militares que dieron el golpe de Estado en octubre de 1979; y entonces vino la guerra.

El conflicto bélico cortó la era de los planes de desarrollo quinquenales; hubo programas trienales de acuerdo con un sistema de ensayo y error, porque los hechos de guerra, la conflictividad política interna y el impacto de la economía internacional nos enrumbaron hacia grandes desequilibrios micro y macroeconómicos. No era fácil administrar una economía "en guerra" o una economla "de guerra"; tema enlonces debalido. El año de 1989 se caracterizó más por la búsqueda de chivos expiatorios que por una leal autocrítica.

Pareciera que en 1989 regresamos a la era de la planeación. Pero este plan, 1989-1994, era un hibrido, inspirado literalmente en un documento de Fusades: "Hacia una economía de mercado: bases para una nueva estrategia de desarrollo económico y social" (mayo de 1989). El regulador de la economía no sería el plan sino los cuatro postulados económicos: (1) La propiedad privada es condición necesaria para la eficiencia de la producción. (2) El mercado libre asegura la mejor asignación de los recursos. (3) La competencia garantiza el funcionamiento del mercado. (4) El Estado tiene un papel subsidiario. Un plan hibrido, regulado por el credo neoliberal, que ha demostrado por segunda vez, en dos décadas, no ser el modelo que nos lleve del crecimiento al desarrollo humano integral. Los tres primeros postulados no describen ciertamente los rasgos más generalizados y comunes de la economía salvadoreña, pese a los esfuerzos del Estado por ejercitar el compadrazgo de la subsidiaridad a favor de esos sectores privados (Realidad, 1998; pp. 25-30). Con tales reguladores estaba de sobra el Ministerio de Planificación.

También están de sobra los resultados negativos: un crecimiento "desgastante" porque los montos del deterioro ecológico, equivalentes al 5 por ciento del Pro- 
duclo Interno Bruto (Fusades), superan el valor porcentual de las tasas de crecimiento del Producto Interno Bruto; unas pérdidas directas e indirectas, derivadas de la violencia, equivalentes en 1995 al 13 por ciento del PIB (UCA-BID; El Diario de Hoy, 7 de junio 1998; p. 4). Un sensible rezago tecnológico en la inversión productiva del sector privado (Conacyt), que ha diezmado las líneas de nuestras ventajas competitivas, y una creciente terciarización económica, alimentada por la orientación del crédito del sistema bancario (ECA, 1997; pp. 800817). El Plan de nación replantea el "nudo-gordiano" de la pobreza estructural, de la marginación sociocultural, aunque a la inequidad y riqueza estructural las califica con el eufemismo inofensıvo de "desequilibrios históricos" (p. 24). Por añadidura, tampoco ha habido un espacio y una voluntad ávida de recuperación moral, desde que una ley de amnistía se empeña en poner la capucha del silencio al informe de la comisión de la verdad. Tampoco ha jugado el mercado del perdón por escasez de demanda.

\section{Planificación del crecimiento}

Casi todos estamos de acuerdo en que no se puede confundir crecimiento con desarrollo porque, a nivel nacional y mundial, se da el primero y no se logra lo segundo. Siendo objetivos distintos y a veces opuestos (crecimiento con subdesarrollo). la pregunta es si la planificación económica puede ensamblar ambas metas. En la práctica de la planificación económica podemos partir de planes pronósticos u objetivos de mediano-largo plazo, realistas y realizables, formulados en forma de tasas de crecimiento globales y sectoriales. Más adelante mencionaremos un instrumento contable útil a tal fin. Bastantes economistas nacionales ponen como un ideal elevar la tasa de crecimiento de un $\mathbf{4}$ por ciento a un 7 por ciento, en la hipótesis de que "el crecimiento es una condición necesaria pero no suficiente para lograr el desarrollo integral".

Para que lo necesario se traduzca en lo suficiente hay que referir estos pronósticos a objetivos humanos y sociales: reducción de la pobreza por la vía de la generación de empleo y reducción de la inequidad por medio de políticas redistributivas fuera del juego mercado. Si el gran factor de producción, hoy y siempre, es el hombre-mujer sanos, instruidos y profesionalmente capacitados, hay que ubicar en el centro de la planificación el consumo y la inversión social. Este objetivo no puede quedar a la merced del "principio del residuo" (lo que quede del presupuesto), ni sometido a los límites del principio de la "subsidiaridad". El consumo y la inversión social son la traducción real del repetido enunciado: todas las personas son iguales ante la ley. No podemos hablar de libertad real y de real igualdad si todas las personas no disponen de esta capacidad económica que emana del consumo social: educación, salud, habitat, seguritad social. 
En una economía de mercado, el consumo-inversión social quedan relegados a los límites del residuo y de la subsidiaridad. Esta es la diferencia lógica entre una economía dineraria y una economía social. Es más fácil y lucrativo calcular la productividad de una innovación técnica a corto plazo que la productividad económica del consumo-inversión social a mediano-largo plazo. Mientras que la economía dineraria busca resultados a corto plazo, la planificación social nos instruye para buscar objetivos a mediano-largo plazo. Mientras que en una economía de mercado el Estado mantiene una posición abstencionista porque todos somos iguales ante la ley, el Estado social de bienestar interviene activamente para que la igualdad legal sea una real igualdad.

La inequidad y la desigual apropiación y expropiación de los frutos del crecimiento es un hecho real a nivel nacional y continental. El Plan de nación alirma que el Estado no sólo debe asegurar la estabilidad macroeconómica y colaborar para que el sector privado desarrolle una oferta ampliada. "También debe actuar de manera más directa y programática para superar los desequilibrios históricos en el acceso de los diversos sectores a bienes y servicios básicos para una vida digna" (p. 24). La Cumbre de las Américas reconoce que éste es un serio problema continental, dando a los "desequilibrios históricos" un nombre propio, la inequidad. "La superación de la pobreza sigue siendo el reto más grande al que se enfrenta nuestro hemisferio. Estamos conscientes de que el crecimiento positivo observado en las Américas en los últimos años no ha solucionado todavía los problemas de inequidad y exclusión social".

El error grave de la declaración de Santiago es que en su primera página reconoce los "beneficios económicos reales en las Américas como resultado de un mayor grado de apertura comercial, de transparencia en las reglamentaciones económicas, de políticas económicas sólidas, consistentes con una economía de mercado", y en la página siguiente los presidentes signatarios se ven forzados a decir que el relo mayor sigue siendo la pobreza, la inequidad y la exclusión social. La única conclusión lógica es que las polf́ticas económicas consistentes con una economía de mercado siguen creando la inequidad y la exclusín social. En América Latina, el modelo dominante ha sido la economla de mercado y no podemos culpar de estos resultados a las economías centralmente planificadas. Baste leer la publicación "El neoliberalismo en América Latina" (Realidad, 1996, No. 54. pp. 747-763). El credo neoliberal se afianza afirmando que la economía de mercado "no ha solucionado todavfa los problemas de inequidad y exclusión social". El dogma se resiste a la verdad.

Implícitamente, la Cumbre de las Américas acepta que sí puede haber algún problema: "La globalización ofrece grandes oportunidades para el progreso de nuestros países y abre nuevos campos de cooperación para la comunidad hemisférica. Sin embargo, puede también incidir en un aumento de las diferencias entre los países y al interior de nuestras sociedades. Firmemente decididos a 
aprovechar sus beneficios y a enfrentar sus retos, otorgaremos especial atención a los países y grupos sociales más vulnerables de nuestro hemisferio". Todas estas declaraciones significan, cn el fondo, que se hace necesario controlar, coregir y reestructurar las sólidas políticas consistentes con una economía de mercado. Más adelante, los signatarios adquieren otro compromiso que no esı́a acorde con la praxis neoliberal: "Proporcionaremos un mayor apoyo a las micro y pequeñas empresas, promoveremos las normas laborales fundamentales reconocidas por la Organización Internacional del Trabajo (OIT)".

Los presidentes signatarios siguen balanceándose en la cuerda floja: mercado sí, pero no del todo. No acaban de desprenderse de los dogmas, mientras que en Europa occidental se multiplican las críticas a la globalización neoliberal y se inclinan por una actualización renovada del Estado Social de Bienestar (ECA, 1996, pp. 865-887). Ampliando el horizonte en que juega la globalización, a la historia del continente agregamos otra historia continental.

\section{Modelos con pies de barro}

A modo de paréntesis anecdótico agregamos un nuevo ejemplo. En la Cumbre de las Américas se hace referencia tangencial a la crisis bursátil de octubre de 1997. "La volatilidad de los mercados de capitales confirman nuestra decisión de fortalecer la supervisión bancaria en el hemisferio, así como establecer normas de divulgación y revelación de información para los bancos". Aquí hay un problema más de fondo que las trucias de Insepro-Finsepro. En la Cumbre de las Américas, así como en nuestros diarios matutinos, se hace y se hizo una referencia a los efectos financieros de la crisis bursátil de oclubre de 1997, pero muy pocos se atrevieron a decir que esa crisis se originaba en países, tigres o dragones, que se nos proponían como modelos económicos para el tercer mundo.

Por cierto que los cómplices de este silencio cometen dos errores. En primer lugar, que esas economías, tigres o Jragones, no nacen de acuerdo con las normas y manuales del libre mercado: "estos paises parten de un entrelazamiento estrecho entre dos grandes burocracias, es decir, entre la burocracia estatal y las burocracias empresariales. El Estado utiliza todas las políticas tradicionales y proteccionistas para forlalecer las empresas nacionales y que puedan expandirse en el mercado internacional. No surgen por sometimiento al proceso de globalización, sino más bien para su aprovechamiento" (Hinkelammert, Frank, $E C A$, 1997, pp. 805-806).

Integrados al proceso de globalización se nos proponían como modelos: su potencial de crecimiento, su agresividad comercial, su acumulación de capital, su libertad de precios, su peculiar sistema educativo... "Pero ante todo, este «modelo asiático» ha despreciado otros asuntos de primera magnitud que no liguraban en la agenda de prioridades de sus hagiógrafos: la cohesión social y las libertades políticas clásicas para sus ciudadanos: no permiten la disidencia. 
La amenaza a la política de libre mercado en toda la región es bien real. Ya se dan diversos efectos: tensión social, inestabilidad polftica... El rápido crecimiento ha creado y ocultado las tensiones sociales. Pese a enormes logros en la mitigación de la pobreza, para los habitantes de la zona son patentes profundas desigualdades. Existe un amplio resentimiento frente al «abismo de riqueza» entre una minoría plutocrática y los desfavorecidos" (Realidad, 1998, pp. 21-22).

El mes de mayo ha sido testigo de las agitadas protestas y convulsiones sociales en Indonesia, Tailandia, Corea ..., creadas y no solucionadas por las leyes del libre mercado. Pasadas unas semanas, "Tras la siembra de los vientos" llegan las tempestades a otras grandes naciones del continente asiático: India, Pakistán y algo se forja en el subcontinente chino: el recuerdo de Tiannamen. El autor del artículo entrecomillado hace suyo una interrogante mundial: "Tras años de globalización y de disciplina de las sociedades en aras de los objetivos macroeconómicos, cuyos frutos de prosperidad sólo una minoría del planeta disfruta, los conflictos sociales y políticos vuelven a plantear las eternas preguntas: crecimiento para qué y para quién, qué pasa conmigo, quiénes somos, adónde vamos, de dónde venimos. Y ante la falta de respuesta, cansada de racionalizaciones tecnocráticas, la gente rompe. Y políticos de todo pelaje, desde mesiánicos convencidos a demagogos manipuladores, saltan sobre la ola de descontento que está echando al traste el sueño neoliberal de un mundo unificado en tomo a un pensamiento único"... (El Pais, jueves 4 de junio de 1998).

También en esos páses, agregando la enorme Rusia, contrastan la alta tecnología con la expandida pobreza. Aunque Africa sea el continente más pobre, el mayor número de pobres subsisten en Asia. Ahora es en Asia donde se desatan las grandes tempestades, la mayoría de ellas inspiradas en una simbiosis de nacionalismo religioso o confesional. De acuerdo con los sucesos del mes de junio, Manuel Castells llega a la afirmación siguiente: "La exclusión de una gran parte de la población del nuevo modelo de desarrollo está generando reacciones en cadena que, en último término, devuelven a los Estados a su instinto básico: amenazar con matar... Y en esa situación, marcada por la contradicción explosiva entre el desarrollo dinámico de una minoría globalizada, la exclusión de una parte considerable de la población y la situación de un sector público insostenible, donde se movilizan movimientos fundamentalistas religiosos, fuerzas nacionalistas, ejércitos nerviosos, partidos desgastados y corruptos, mafias criminales y especuladores financieros. Ese es el mundo real que se configura en torno a la crisis dè desarrollismo asiático".

La imagen de la globalización y del mundo como un mercado sin fronteras no encuadra en la realidad del mosaico de nacionalismos; los unos nacen como movimientos centrífugos de pasados regímenes centralistas (URSS), los otros integran un componente religioso, incluso fundamentalista, y en muchos de ellos se alimenta la xenofobia. Y sobre este mosaico desintegrado, la globalización 
que predica una economía sin fronteras levanta fronteras en el interior de cada economía. Esta es nuestra experiencia nacional.

\section{El Salvador son dos}

En la línea de la planificación del crecimiento, en este acápite se pretende dar otra traducción a los "desequilibrios históricos" de que nos habla el Plan de nación. Los autores de este plan han querido confirmar, con una serie de entrevistas departamentales, que el nudo gordiano nacional es la pobreza y la exclusión sociocultural. Los resultados de estas encuestas se resumen en los recuadros siguientes.

Chalatenango: afirman que los mayores problemas son el desempleo, la marginación departamental y la exclusión social, así como la deforestación. La Unión: los problemas que deben resolverse son la incomunicación departamental, la marginación de la zona y la ausencia de inversión económica y social. Usulután: entre los problemas fundamentales que exponen sus habitantes están el desempleo y la pobreza. Cabañas: sus problemas principales son el desempleo, la pérdida de recursos naturales y la pobreza. Auachapán: sus principales problemas son el desempleo, la reducida participación ciudadana y el estancamiento de la agricultura en pequeño. Morazán: los problemas que identificaron son la marginación económica, social y cultural de la zona, el desempleo y la extrema pobreza. En algunos departamentos se señala también el problema del analfabetismo así como la delincuencia (La Prensa Gráfica, martes 19 de mayo 1998).

El Salvador son dos y la pobreza estructural tiene su mayor habitat en el sector agrario. De acuerdo con datos del PNUD, la pobreza rural afecta al 64.8 por ciento de los hogares, mientras que la pobreza urbana afecta al 42.3 por ciento de las familias. En otras palabras, el crecimiento macroeconómico, de que nos hablan los documentos gubernamentales, no encuentra vias de comunicación hacia aquellos departamentos. En el mismo informe, 1997, que mide el índice de desartollo humano, se concluye que el ingreso en las áreas urbanas es, en promedio, tres veces mayor al de las áreas rurales. Se dan grandes diferencias entre los departamentos exiremos. Por una parte, los índices de desartollo humano de los departamentos de Morazán, Cabañas y La Unión los coloca al nivel de los países africanos como Guinea Ecuatorial y muy ccrcanos a los bajos niveles de desarrollo de Haití. Por otra parte, San Salvador está por encima del promedio nacional y se encuentra arriba de un país como Perú. Esto nos indica otro gran desatío, que es el desarrollo regional y local" (ECA, 1998, p. 334).

Se trata realmente de un desequilibrio histórico. La guerra de doce años se libró en estas zonas; aniquilo, en lonna brutal, miles de vidas humanas y destruyó sus principales recursos naturales. La marginación social venía desde antes: nuestra economía inicialmente fue agrícola con su historial de expropiaciones y 
apropiaciones. Los grandes flujos de divisas, creados por las exportaciones tradicionales, nunca se tradujeron en sensibles mejoras de los salarios mínimos. Buena parte de esos excedentes se invintieron en la naciente industria, en el gran comercio y sobre todo en la banca privada y la especulación de bienes inmuebles. El desarrollo de las actividades urbanas y su mayor nivel de empleo se asientan en la desolación y el desempleo estructural agrario. Al hablar de la "deuda agraria" surge una pregunta: ¿quién debe a quién'? Es triste que la única salida que le queda al desempleo estructural es seguir la ruta del dinero: integrarse en el hacinamiento urbano. No parece fácil dar una solución a la aglomeración urbana sin iniciar un proceso de urbanización agraria. De momento no se ven signos efectivos de una política de reaclivación agraria. Los hemos olvidado.

Si deseamos reiniciar una planeación del crecimiento con desarrollo hay que partir de los resultados derivados del juego de la globalización: un crecimiento con mayor desigualdad y exclusión y un regreso defensivo a la identidad nacional, enraizado muchas veces en fundamentalismos religiosos. Parece acertada la tesis de A. Schlesinger, quien fuera asesor del presidente John Kennedy: "El mundo de hoy está desgarrado en direcciones opuestas. La globalización ocupa el puesto de mando y dirige a la humanidad, pero -al mismo tiempo-impulsa a las personas a buscar refugio frente a sus poderosas fuerzas que están más allá de su control y comprensión. Se retiran a unidades familiares, inteligibles, protectoras. Anslan la política de la identidad. Cuanto más rápidamente se integra el mundo, más personas se refugiarán en los enclaves religiosos, étnicos o tribales. La integración y la desintegración se alimentan mútuamente" (Realidad, 1998, p. 19).

\section{Hacia la integración económica}

Puesto que el concepto de integración económica tiene un doble significado, interno y regional, nos referimos en este momento a la creciente desintegración económica interna que se ha profundizado aún más en las dos últimas décadas. En un artículo reciente, dedicado a la naturaleza del crecimiento, tratamos de mostrar que la locomotora de nuestro crecimiento se ve frenada por una serie de "coyunturas" (en su sentido etimológico) que la han empujado a la vía muerta de la desintegración sectorial. Crecimiento frenado con rasgos de estanflación; crecimiento desgastante, donde el deterioro ecológico equivale al 5 por ciento del Producto Interno Bruto; crecimiento con desempleo y desigualdad; crecimiento no armónico en razón de la creciente terciarización económica; crecimiento que no encuentra "nichos productivos" en los sectores tradicionales, debido al rezago y rechazo de la inversión tecnológica, y que busca su excedente de beneficio en la inversión especulativa de la privatización y del mercado financiero. Con ello hemos pasado de una economía basada en el trabajo y la producción a una economía asentada en la importación y especulación ( $E C A$, 1997, pp. 799-817). 
Bases para un plan de nación se hace eco de la prolunda desintegración y nos lleva a las discusiones y propuestas que en 1993 hacían algunos institutos de investigación en el momento de publicarse la matriz insumo-producto de 1990. El tema de la integración cconómica aparece en dos acápites del Plan de nación: "una sociedad con una cconomía integradora y competitiva" (p. 14) y "Delïnición de áreas priorilarias de desarrollo" (p. 29). Esla discusión tiene su historia en las propuestas de Cenitec, IIES-UCA, Funde. ANEP y Fusades (ECA, 1997. pp. 811-815).

He aquí algunos textos del Plan de nación que recogen recomendaciones de aquellas propuestas: "El país no puede continuar transitando sin una apuesta estratégica en torno a su base productiva" (No. 35). "No podemos apostarle a todo, y como toda opción ello implica dar prioridad a unas cosas y no darles a otras. Definir las áreas prioritarias de desarrollo para nuestro país no es un asunto fácil y requerirá de una profunda discusión y sólidos compromisos. Esto debe hacerse con la participación de todos los sectores y en el marco de los principios de libertad y responsabilidad" (No. 38). "Los criterios fundamentales para la definición de las áreas prioritarias deben ser: los efectos multiplicadores sobre el resto de la economía, las oportunidades de inversión, el logro de equilibrios sectoriales, la integración económica del país y las ventajas competitivas" (No. 39). Este último numeral es importante para nuestro propósito.

El mismo desafío es recogido al recomendar una "economía integradora", en la que "Ios distintos sectores productivos se articulen; los frutos del crecimiento se aprovechen de manera más equitaliva, en el marco de los principios de libertad y responsabilidad, al tiempo que se vinculen a las dinámicas de inversión más convenientes para el desarrollo; las distintas zonas del país se encuentren articuladas a la aclividad económica nacional; funcionen sólidas cadenas productivas empresariales; los flujos financieros, comerciales y tecnológicos incluyan de manera especial a los micros y pequeños empresarios; las necesidades del mercado externo se conjuguen adecuadamente con las del mercado interno" (No. 17).

En este articulado hay una frase iluminadora para esclarecer el modo de planificación económica que deseamos: aquella que conjugue la libertad con la responsabilidad, es decir, una libertad responsable. En Europa occidental se le llamó economía concertada, economía mixta, economía democrática, planificación indicativa. El Plan de nación to resume con otras palabras: "La falta de acuerdos básicos alimenta la incertidumbre y la dispersión de esfuerzos. La dinámica mundial nos exige concentración y coherencia en los esfuerzos. En la medida en que se posterga la decisión nacional sobre las actividades con mayor potencialidad para el país, se desaprovechan recursos y se pierden oportunidades y ventajas en relación al desarrollo nacional y la vinculación al mercado internacional" (No. 36). Sea dicho, entre paréntesis, que este numeral es una crítica bastante clara al laissez-faire y a la improvisación del presente gobierno. 


\section{Volvamos a nuestra contabilidad nacional}

Los párrafos citados del Plan de nación se refieren directamente a uno de nuestros instrumentos de la contabilidad nacional: las matrices insumo-producto o matrices intersectoriales. Sin embargo, llama la atención que el propio Banco Central, que las elaboró, así como olras instituciones públicas hayan hecho escaso uso de estas matrices para sus análisis de estructura económica. El Dr. Joaquín Arriola presentó un análisis aplicado de la matriz 1990, subrayando los ejes o sectores más competitivos o dinamizantes de la economía (Funde, septiembre de 1994). En el Departamento de economía de la UCA hicimos varios estudios y análisis comparativos de las matrices insumo-producto 1978 y 1990.

Es cierto que ambas matrices aparecen en tiempos inoportunos: la matriz 1978 se publicó en 1986, cuando estábamos más preocupados por la supervivencia de las personas y de la economía nacional. La matriz de 1990, confeccionada en 1993, se publicó en 1995, cuando soplan aires nuevos de economía de libre mercado, dolarización, aranceles, privatización, IVA y otras políticas sorpresivas. Sigue llamando la atención que el Banco Central, editor de estas matrices y que cuenta con excelentes economistas, no haya prolongado la edición con análisis estructurales actualizados que hubieran enriquecido los programas monetario financieros anuales. Se impuso la publicidad superficial o de la superficie macroeconómica sobre el análisis estructural del esqueleto económico.

Apoyamos las recomendaciones del Plan de nación porque unas matrices actualizadas, 1991-1997(?), nos ayudarían a descubrir el grave sesgo de nuestra desintegración económica, interna y externa, y a trazar sendas para el desarrollo. W. Leontief decía que los países pobres son pobres no por falta de recursos, sino por no saber cómo utilizarlos. Las matrices son algo así como un libro de cocina económica. En síntesis, ¿qué nos aportan las matrices? Las matrices nos dan la red de intercambios de todas las ramas productivas; qué sectores aparecen como posibles dinamizantes de la economía por ser más demandantes y/o más oferentes de insumos al conjunto de la economía (triangulación de la matriz). Este dato es el referente orientador del efecto multiplicador de la inversión y del multiplicador del crédito. Tendríamos un detalle bastante preciso de las importaciones claves, aquéllas que suministran insumos a más sectores económicos, a preferenciar por el crédito bancario, restringiendo otras importaciones costosas e innecesarias. Descubrimos sectores capaces de transformar insumos importados en exportaciones finales.

Un dato muy importante, señalado en el Plan de nación, es que las matrices nos ofrecen una visión de la estructura geográfica o distribución territorial de los procesos productivos; con ello ayudan a descubrir lo que $\mathrm{W}$. Leontief llamaba bloques o familias industriales y que hoy Ilaman clusters. Este aporte matricial sirve para planificar un desarrollo equilibrado de las regiones y ahorra tiempos y movimientos del proceso productivo en el espacio nacional, de la misma manera 
que los ingenieros industriales planifican la organización en planta de las empresas. Este aporte espacial de las matrices nos serviría para descubrir posibles polos de desarrollo a través de las agroindustrias. Cuando hacíamos análisis comparativos de nuestras matrices 1978 y 1990, veíamos que la parte superior de la matriz, con numerosas "casillas fantasmas" (sin intercambios sectoriales), reflejaba la desolación y el abandono del sector agrario, de tal forma que el flujo mayor de intercambios se concentraba dentro y entre los sectores secundario y terciario, es decir, en las zonas urbanas del país.

Las matrices nos presentan los coeficientes técnicos de producción que, por una simple regla de tres, nos describen la tecnología y la estructura de costos de cada rama productiva. Por cierto, el Banco Central no hizo pública esta sábana de la matriz de 1990, aunque sí la había elaborado. Con ello pudimos deducir que entre 1978-1990 (años de guerra civil) no habíamos evolucionado en nuestra estructura tecnológica y entrábamos con un serio rezago en las ondas de la globalización (Conacyt). Citando una vez más a W. Leonlief, él recomienda analizar los coeficientes técnicos de producción de países económicamente cercanos para aprender nuevas recetas culinarias económicas.

Puesto que junto con el crecimiento armónico se busca un crecimiento más equitativo, el análisis comparativo de las remuneraciones factoriales integradas en el valor agregado nos muestra si en verdad se ha dado un crecimiento con equidad. Nuestros análisis comparativos 1978-1990 nos mostraban un crecimiento con mayor desigualdad (Realidad, 1994, No. 39, pp. 310-312; Realidad, 1995, No. 44, pp. 328-330). Sobra decir que el análisis comparativo de ambas matrices patentizaba el deslizamiento hacia una profunda terciarizacion. A modo de ejemplo curioso, uno de los mayores ingresos de exportaciones provenfan de las llamadas de ANTEL, que al tener un elevado excedente de producción bruta aparecía como un candidato virtual para su privatización.

Si dispusiéramos de la última sábana de los coeficientes directos e indirectos, o coeficientes invertidos, que aparecían en la matriz de 1978 y no en la de 1990 , contaríamos con un radar valioso para la planeación del crecimiento futuro. A estas posibles aplicaciones de la matriz vale la pena agregar un pequeño descubrimiento. Utilizando la malriz 1978 y siguiendo por seis años el efecto multiplicador de una inversión estatal de 100 millones de colones para generar empleo en sectores desempleados, descubrimos dos cosas: primero, que el efecto multiplicador de esa inversión era $2.72(k=1 / 1-c)$; segundo, que ello se debía a que los sectores productivos de bienes típicos de la canasta familiar son sectores con capacidad dinamizante de la economía. En otras palabras, la demanda popular del mercado interno es una de los ejes dinamizantes de nuestra economfa ("Necesidades básicas y reactivación de la economía", Boletín de Ciencias Económicas y Sociales, año X, No. 4, julio-agosto, 1987, pp. 226-251). 
Al comentar estas aplicaciones matriciales no estamos hablando de la resurección sino de la reencarnación de este instrumento de la contabilidad nacional, que históricamente se ha utilizado en todos los modelos y sistemas económicos. W. Leonlief, de origen ruso, redicado en Harward, decía que en la URSS se utilizaron las matrices como un instrumento de la planificación económica centralizada; W. Leontief se estrenó en la década de 1920 con el sistema de balances y eslabones, practicados inicialmente en la URSS. En Europa occidental se utilizaron para la planificación concertada e indicativa. Donde más se desarrollaron las matrices fue en Estados Unidos, y quienes más las utilizaban eran las grandes empresas para ubicarse en los seclores claves de la economía. Por ello, John $\mathrm{K}$. Galbraith dirá que la economía norteamericana está planificada por la gran empresa. Las matrices intersectoriales se parecen a la aspirina, que evitan dolores de cabeza bajo cualquier modelo económico. Nuestro modelo económico sigue con sus dolores de cabeza y con sus pérdidas de memoria porque, entre otras razones, ha preferido navegar sin un radar económico.

\section{Recomendaciones al Banco Central de Reserva}

Hemos comparado las matrices intersectoriales con la aspirina que suprime los dolores de cabeza, pero que no suprimen sino presuponen que hay una cabeza. Las matrices intersectoriales son un instrumento de solución económica, pero no suprimen sino que presuponen que hay una cabeza económica. Por ello y de acuerdo con los objetivos señalados por el Plan de nación, para llegar a ser una sociedad integrada e integradora queremos solicitar al Banco Central que tenga a bien actualizar ese excelente trabajo realizado en 1993-1995. En los considerandos de la Ley Orgániza del Banco Central se establece que las políticas monetarias, cambiarias y crediticias promuevan y mantengan las condiciones más favorables para el desarrollo ordenado de la economía nacional; que aseguren la estabilidad y el crecimiento de la economía. Dificilmente las políticas monetarias lograrán estos objetivos si no se cuenta con un instrumento radar que le marque el rumbo del desarrollo ordenado de la economía. Sin este instrumento orientador, las decisiones del crédito obedecerán a criterios de corto plazo, determinados por la simple rentabilidad. Es algo patente y paradójico que el crédito bancario no ha seguido los cauces de la dinamización económica general, sino los cauces de maximación de sus propios beneficios. El hecho de que en la revista trimestral del Banco Central aparezcan las 44 ramas productivas del pais, con sus respectivos valores de la producción bruta, consumo intermedio y valor agregado, deja entrever que cuenta con los datos básicos para trasladarlos a la forma matricial o intersectorial, similar a la matriz 1990, y poder así derivar los coeficientes técnicos de producción. Esta base de datos es lo que requiere el Plan de nación para poder estimar qué áreas serían ahora las prioritarias, qué sectores muestran mayor capacidad de poner en marcha el efecto multiplicador $y$, en consecuencia, por dónde debiera canalizarse el hoy sesgado crédito bancario. 
Valga avalar esta solicitud con dos recomendaciones que, desde 1994, hacían ANEP y Fusades. En su "correo económico", octubre de 1994, ANEP advertía: "De darse un aumento en los mismos (encajes legales e intereses), los efectos sobre la inversión serían aún mayores que en la aclualidad. Debe recordarse que, debido a la evolución de la economía salvadoreña, los márgenes de ganancia en actividades dedicadas a la atención del comercio y de los servicios son mayores que en el resto, lo que de por sí es un sesgo en lo que se refiere a la dirección del crédito, en contra de las actividades industriales y de producción en general, ya que su mayor período de maduración y menor margen de ganancia las vuelve menos atractivas para el sistema financiero" (ECA, 1997, p. 813).

Por las mismas fechas y desde su 6ptica económica, Fusades vuelve a recordar el sesgo del crédito al comentar la política cambiaria: "A manera de antecedentes cabe señalar que el panorama económico a finales de 1994 es positivo en términos de estabilidad de precios y de incremento real, con tasas cercanas al 5 por ciento. No obstante, el incremento productivo estuvo liderado por sectores de bienes no transables, a saber servicios, comercio y construcción. Dicho patrón de crecimiento no es sostenible a mediano y largo plazos, porque se da con menor participación de las principales actividades que generan valor agregado, divisas y empleo. Estas actividades corresponden a la actividad manufacturera y la agricultura, que son las dos bases de la estructura de exportación, o sea, de bienes transables, que es lo que podría mantener el desarrollo sostenido de la economía, según Fusades lo ha venido señalando" (Ibídem, p. 813).

Ambos textos se integraban en el artículo citado al comentar el problema de nuestra terciarización económica, que tanto el Plan de nación como las instituciones citadas desean corregir, si queremos sentar las bases de un crecimiento sostenido. Por supuesto que la disposición de este valioso aporte del Banco Central, unas matrices actualizadas, no subsanaría la presente desintegración económica, pero sí nos ayudaría a percibirla con mayor detalle. La macroeconomía tan global o tan superficial utilizada por las instituciones oficiales estaba vedando la entrada a la desintegración sectorial, y llamaban sana, fuerte y sostenible a una economía sectorialmente quebrantada.

En ese entorno situamos la función de esa institución de planeación económica, ministerio o secretaría, cercana al gobierno central, que sirviera de puente entre la administración pública y los sectores productivos del país, sectores formales e informales, de donde pudiera surgir el verdadero plan de desarrollo nacional. Es necesario volver a la planeación económica concertada, aunque sólo fuera por una simple razón: que el Estado y su gobierno conozcan cuáles son los auténticos problemas del país. La verdadera modeınización del Estado se centra en que el Ejecutivo conozca y sea sensible a los modernos problemas de la nación: que acompañe y dirija la historia de la nación. No es cuestión sólo de más o de menos, sino de otro estilo de Estado que se asienta en un modelo de 
planeación económica democrática. Por lo tanto, entra en juego la reflexión sobre un nuevo mecanismo de funcionamiento económico, a partir de los resultados del modelo presente, con miras a delinear una alternativa más social al neoliberalismo imperante.

\section{Del "laissez faire" al "laissez passer"}

A dos siglos de distancia recordamos el grito de los fisiócratas: "laissez faire, laissez passer: le monde va de lui-même" (déjennos actuar y déjennos comerciar libremente: el mundo tiene un orden y sigue su curso). Un grito de libertad luego de tres siglos de mercantilismo controlado por las coronas de los nuevos Estados. Con estas consignas se abrían las puertas al liberalismo de mercado. En mayo de 1989, fecha en que se derruye el muro de Berlfn, el nuevo gobiemo enuncia los cuatro postulados que regularán la actividad económica: la propiedad privada como condición necesaria; el mercado como el mejor asignador de los recursos; la competencia como la garantía del mercado, y un Estado reducido a una función subsidiaria.

Los cuatro postulados económicos venían precedidos por cinco principios filosoficos, cuyo fin era legitimar éticamente el juego del mercado: libertad, progreso humano, igualdad, paz social y justicia equitativa. De hecho, no serfan estos principios filosóficos los que inspirarían el juego del mercado, sino que representaban un "rebalse" futuro de los postulados economicos. Los principios filosóficos eran un futuro esperado, mientras que los postulados económicos determinaban la ética del quehacer presente. No quedaba otra alternativa luego del fracaso del este europeo y éste era "el orden de la historia": le monde va de lui-même.

A los nueve años de aplicar estas consignas nos hacemos dos preguntas: ¿qué frutos nos ha dado este modelo de mercado? y, ¿cuál es el orden que sigue el mundo? La respuesta a la primera pregunta pudiera alargarse con múltiples testimonios; se podría integrar el abanico de respuestas recogidas en las encuestas de opinión pública que, en general, dibujan con color gris-oscuro la situación y la gestión económica. También se podría recurrir a la valoración que el gremio empresarial manifesto, a inicios del año, en los rotativos matutinos: "Economía crece, pero no suficiente. Afirman hubo crecimiento con desempleo. ASI insatisfecha con crecimiento del 4.5 por ciento. Necesidad de más reformas estructurales"... (El Financiero, La Prensa Gráfica). Estos y otros testimonios son parámetros valiosos que, por cierto, no manifiestan un parabién aprobatorio de parte de los gremios empresariales ni de las clases populares.

Otra forma de responder a esta primera pregunta es ver, en diagonal, cómo el gobierno trató de asentar las bases de una economía de mercado. Se nos dijo que ese era el modelo ideal y que el sector privado estaba en capacidad de entrarle al modelo ideal. En el caso nacional se alteró el turno de los actores, porque en 
1995 fue el gobierno quien se adjudicó la función del laissez-nous faire. El gobierno dijo que El Salvador tenía que ser el pals de la maquila: primera abertura. Dijo que el dólar debía hacer la función de termostato de la emisión monetaria, para que la economía no se recalentara ni se enfriara: segunda abertura. Dijo que se reducirían los aranceles a la importación para que nuestros empresarios se despertaran con la competencia externa: tercera abertura. Dijo que se iban a traspasar algunas instituciones de servicios públicos a la administración de la propiedad privada, exıranjera y nacional: cuarta abertura. Dijo que estas reformas tenían costos elevados para el Estado que debería pagar la nación; en forma sorpresiva y sospechosa se pacta la elevación del IVA en un lugar muy simbólico: las ruinas de San Andrés.

No quedó muy claro en 1995 qué parte del laissez-nous faire correspondía al sector privado. Este sector no veía nada claro el proyecto de la dolarización; era algo demasiado técnico que podía interferir el libre manejo de la moneda nacional. No se oponfa a que algunos sectores se dedicaran a la maquila, aunque sin demasiadas prebendas competitivas. Se resistió, en cuanto pudo, a la reducción de los aranceles porque calculaban que esa medida iba a entorpecer su laissezfaire intemo. Aplaudían los proyectos de privatización porque abrían una nueva puerta a la valoración de su capital; pero se opusieron (con la mayoría del país) a la elevación del IVA que, traducido en alza de precios, debilitaría aún más la demanda deficiente. Este ejercicio del laissez faire, de parte del gobierno, más bien desconcertó al sector empresarial, a la nación en general, al mismo tiempo que el auge aparente 1992-1995 quiebra a mediados de ese año dando vía abierta a un ciclo de recesión económica.

El segundo discurso presidencial, junio 1996, deja claramente entrever que no estábamos preparados para entrarle a una economía de mercado, y que dicha economía no rendía "todavía" los frutos esperados. El discurso presidencial marca los contrastes entre lo global y lo estructural: "Sabernos que la situación macroeconómica se mantiene fuerte y saludable, pero reconocemos que en los meses recientes el rilmo de la economía se ha vuelto más lento, y aunque estamos lejos de una recesión económica, es innegable que el costo de la vida ha ocasionado una natural preocupación. tanto al gobierno como en los distintos sectores de la sociedad".

En la parte linal del discurso, y a solicitud de los gremios empresariales, se prometen doce medidas económicas, algunas develan serias fallas estructurales de nuestro sistema productivo. Se promete incrementar líneas de crédito a la micro y pequeña empresa, tal como lo vuelve a recomendar dos años más tarde el Plan de nación. Se anuncia un plan integral de reactivación agropecuaria, plan que se sigue retormulando en 1998. Se promete la implementación de un programa nacional de competitividad para dignificar la calidad del producto nacional, pero hay resistencia a la inversión tecnológica y nuestra balanza comercial sigue 
deficitaria. Se llevará a cabo una intensa promoción del país en el exterior, pero la permanente violencia sigue polarizando la imagen nacional. Se promoverá una adecuada liquidez en el sisterna financiero, más créditos productivos y menores tasas de interés; pero el sector bancario sigue financiando la terciarización económica. Se destinará el producto de la modernización (lea privatización) de las empresas del Estado a infraestructura y gasto social, que generen nuevos empleos y beneficie a los más pobres. Hasta el momento no se han visto tan buenos efectos y las privatizaciones, más bien, han reducido los empleos.

A las promesas de 1996 tenía que seguir el discurso de 1997. El resultado de las elecciones, marzo de 1997, no era el mejor preludio para el discurso de junio de 1997. Dentro de los límites permitidos a la propia interpretación, este discurso venía a reconocer que no estábamos capacitados ni entrenados para el juego del mercado y que el juego del mercado nos había desconcertado. Había que solicitar la ayuda de un Plan de nación, que nos diera una visión a mediano y largo plazo y generara estabilidad, confianza y continuidad. El año de 1997 fue el año de "bases para un plan de nación". Con ello, el cuarto discurso de junio de 1998 no ha tenido mayor resonancia. Se centra en las estadísticas cuantitativas sobre los gastos del presupuesto nacional; se reconoce que la delincuencia sigue siendo uno de los más serios problemas que afectan a la colectividad nacional, y se anuncia que dentro de un año "tendré la inmensa satisfacción de entregar la Presidencia de la República"... La lectura transversal de estos hechos y discursos del presidente y de su gobierno dan pie a diversas reflexiones. Se votó por una economía de mercado, por una economía abierta hacia fuera. Se escogió el lema del laissez-nous faire, pero lo votantes de este lema han mostrado o demostrado que no están capacitados para atenerse al juego del mercado: calidad, innovación, tecnología y normas de producción. Nuestro entorno es bastante distinto: deterioro ecológico, rezago tecnológico, terciarización económica e inversión especulativa. Tarnpoco los postulados económicos han generado el "rebalse" de la igualdad, del progreso humano, de la paz social, de la justicia equitativa y de la libertad real.

Sin embargo, los autores intelectuales del modelo, sean ellos externos e internos, sí han logrado en buena parte sus objetivos teóricos y prácticos. En el orden teórico, convencer a importantes sectores del país de que éste es el ideal por seguir, pese a los iniciales tropezones. En el orden práctico la victoria es mayor: el resultado más patente es "el paso al laissez faire y al laissez passer" de los otros. Las aperturas programadas no han propiciado sensiblemente nuestro "propio hacer", sino más bien han alimentando el "quehacer externo" desde la importación comercial hasta la inversión extranjera en los servicios sociales privatizados. Son muchas las personas que comienzan a ver con temor esta irivasión externa como un primer peldaño del nuevo orden internacional.

Es lógico que en este entorno de perdedores querramos volver a un modelo asentado en la planeación del desarrollo económico; un modelo que nos ayude a 
recuperar la identidad nacional. Países del primer mundo, conocedores del movimiento neoliberal, lo están haciendo y hablan de reestructurar un Estado social de bienestar. La planeación nacional es totalmente necesaria porque este paso hacia el "dejar hacer y dejar comerciar" de los olros es el preámbulo del nuevo orden internacional, que busca eliminar las mismas identidades nacionales. Por desgracia muchos gobiernos se prestan a colaborar con este proceso de desnacionalización llamado el fìn de la historia.

\section{La integración y la desintegración se alimentan mútuamente}

Esta frase de A. Schelesinger describe acertadamente la tensión del mundo actual. La cumbre de Conpenhague señalaba, a nivel mundial, el problema de la exclusión del trabajo, de donde dimana la generalización de la pobreza y del crecimiento con desempleo. La atomización social y la insolidaridad caracterizan el nuevo orden internacional. A la exclusión del trabajo se agrega la exclusión de los mismos Estados. A. Schlesinger lo condensa en un breve párrafo: "Un objetivo de la actividad capitalista es la economía globalizada. Un candida10 - no previsto- para la desırucción capitalista es el Estado nacional, tradicional asiento de la democracia. El ordenador (revolución informática) convierte el mercado $\sin$ trabas en un monstruo global irresistible que alraviesa las fronteras, debilita los poderes nacionales de implementación de impuestos y regulaciones. impide la gestión nacional de las tasas de intcrés e intercambio, amplía las disparidades de riqueza lo mismo dentro de las naciones que entre ellas; derrumba las nommas laborales, degrada el medio ambiente, niega a las naciones el poder de dar forma a su propio destino económico sin dar cuenta a nadie y crea una economía mundial sin una política mundial. No existen autoridades que proporcionen control internacional. ¿D6́nde está la democracia?" (Realidad, 1998, p. 18).

Desde Venezuela, el Dr. Maza Zavala se expresa en forma contundente al exponer la etapa linal de la globalización: "es decir, cl mundo como un espacio abierto, el mundo como una totalidad, el mundo como el escenario para un juego estratégico en el cual se abstraen las fronteras, se abstraen los intereses nacionales y todo se constituye en el juego de las grandes fuerzas del mercado mundial. Esta es la clapa que corresponde al ncoliberalismo: abatir las fronteras nacionales. Proteccionismo, no: preferencia al mercado interno, no; planificación nacional, no: regulación de la inversión extranjera. no: soberanía monetaria nacional, no. Apertura, abatimiento de cualquier obstáculo a la movilización de factores, mercancías, capitales, adscripción incondicional a los cambios emergentes de los centros mundiales de desarrollo, totalización del juego estratégico; esto es la elapa de la globalización"... (ECA, 1998, pp. 322-323). En nuesiro país se vienen propiciando y aplicando algunas de estas medidas económicas.

Frank Hinkelammert desarrolla el lenómeno de la exclusión de la inversión productiva, en nuestros países, desde el huracán de la revolución tecnológica. El 
presenta al primer mundo de hoy como un "archipićlago", que aparece en todos lados, en el interior de un mar circundante de espacios que ya no pueden integrarse ni económica ni socialmente. Incluso, los países del primer mundo dependen de un crecimiento intensivo, allamente tcenificado, que ha logrado los límites tecnológicos posibles y que puede scguir solamente al paso del surgimiento de nuevas posibilidades tecnológicas y de su aprovechamiento. Los enclaves de este archipiélago conservan una dinámica hacia dentro y una exclusión de otras inversiones produclivas. "Así se explica la tendencia hacia la estagnación dinámica (jobless-growth), el bloqueo al crecimiento del capital productivo, ante la libertad de los hujos de mercancías, productos y capitales". Esto significa que las inversiones productivas de nuestros países pueden bloquearse por el proceso de globalización. Esıas inversiones produclivas requieren ser competitivas para poder realizarse, lo que pocas veces puede lograrse sin protección y fomento; en consecuencia, no sc hacen.

Hinkelammert agrega una acotación importante. "La globalización no es posible sin una acción constanle y decidida de los Estados. Ahora, los Estados funcionan, sobre todo, como instancias de la globalización, que debe facilitar rlujos de mercancías y capitales, y fomentarlos con subvenciones inmensas y que en tamaño superan la cantidad de subvenciones que el Estado social jamás haya efectuado". Este proceso de exclusión de inversiones productivas ha generado la "cacería de la privatización" que, al traducirse en una nivelación de los salarios a la baja y una concentración mayor de los ingresos, incrementa el volumen de capitales disponibles y necesitados de nuevas inversiones especulativas.

Todo el sistema se sustenta en la teoría de las ventajas comparativas. "Esta leoría sostiene que cualquier forma de libre comercio intemacional necesariamente se aplica en ventaja de todos los países que entran en este comercio... Según esta teoría, no es posible que comprar barato sea la manera más cara de comprar. Sin embargo, la transición al estancamiento y después a la contracción dinámica son completamente diferentes. En esta situación, el libre comercio destruye mayores ingresos de los que se generan derivados de la compra más barata. Efectivamente, se compra más barato, pero esta compra lleva a la desIrucción de producción que había permitido delerminados ingresos. Al destruir esta producción, sin sustituirla por nueva y más eficiente, se pierde este ingreso sin ninguna contrapartida igual o mayor"... (ECA, 1997, pp. 804-805).

Estos breves testimonios bastan para mostrar que el proceso de globalización tiende a adicionar la exclusión del trabajo, la exclusión de inversiones productivas nacionales y que los mismos Estados se automutilen y tiendan a ser excluidos en la medida en que, cautivos de estas ideologías, subvencionan este proceso de desnacionalización. 
Este desafio entre integración y desintegración pasa a ser tema de investigación continental. En reciente número de la revista Desarrollo Indoamericano (mayo, 1998, No. 104), los diez artículos y autores de distintos países se centran en el objetivo comun: "Por la formulación de una teoría para el desarrollo económico y social de nuestra América Latina". La cita es una invitación a su lectura. Al mismo tiempo hemos recibido dos documentos preparados por Alberto Arroyo Picard, profesor titular de la Universidad Iberoamericana, con el título: "El reto de consiruir un nuevo proyecto nacional" y "Reflexiones sobre las alternativas a la globalización neoliberal".

Como el protesor Arroyo Picard se ha especializado en el análisis de los tratados de libre comercio internacional, pone al descubierto los objetivos e intereses de las grandes potencias y de sus multinacionales en la formulación de estos tratados: Organización Mundial del Comercio (OMC); Tratado de Libre Comercio de América del Norte (TLCAN); el Acuerdo de Libre Comercio de las Américas (ALCA), cuyo articulado se quiere acelerar en el presente mes de junio, y el intento del Acuerdo Multilateral de Inversiones, donde se legitimaría la suprema protección de la inversión externa. "Los nuevos acuerdos en proceso no tienen nada que ver con la complementaridad económica y la cooperación, sino con el interés de las corporaciones mundiales por integrarse, globalizar su producción y romper las barreras y regulaciones nacionales a la inversión extranjera y en general de los proyectos nacionales de desarrollo".

Aparte del análisis de los intereses imperialistas de estos tratados, y en la línea de la revista Desarrollo Indoamericano, el profesor Aroyo Picard invita al reto de construir un nuevo proyecto y alternativas a la globalización neoliberal. He aquí algunas reflexiones del autor: "Consideramos que este proceso no puede enfrentarse sólo desde procesos nacionales. Es necesario una gran alianza social continental de todos los sectores de la población afectados por él. Frente a la globalización del capital y su proyecto a nivel planetario sólo podremos enfrentarlo con un sujeto social globalizado. El reto es actuar local y sectorialmente pero pensar y coordinarse globalmente".

Este proceso integra una serie de estrategias: (a) Crítica integral del modelo. Sus efectos sociales, su insustentabilidad ambiental y económica; el proyecto neoliberal es incompatible con la dernocracia, por su carácter excluyente, y tiende a sostenerse por la fuerza. La crítica incluye su dimensión ética. (b) Construir una alternativa. Es necesario pasar de la cultura del no o de la simple oposición a la cultura de propuestas realistas; los gobiernos justifican sus políticas afirmando que no hay otra alternativa que la estrategia neoliberal (Cumbre de Santiago). Por ello es necesario construir alternativas más justas éticamente y viables técnicamente. (c) Construir un sujeto social capaz de impulsar dicha alternativa. El reto es no sólo técnico y administrativo, sino sobre todo político: encontrar el sujeto social que saque adelante las propuestas. Un paso desde lo nacional a lo regional-continental. 
"El reto es pues construir y consensar proyectos nacionales de desarrollo justos y sustentables y desde ellos participar en la globalización. Estos proyectos deben ser viables en el mediano plazo y que a la vez creen condiciones para plantearse proyectos de sociedad que superen la lógica del capitalismo. El reto es convertir la crítica en propuesta y la propuesta en proyecio impulsado por un gran sujeto social. El reto es nacional y sectorial, pero a la vez global e internacional... Pensamos en una economía abierta pero con proyecto nacional y por ello nos oponemos al llamado libre mercado. En primer lugar, tal mercado no es libre, sino manejado por un puñado de grandes corporaciones transnacionales. En segundo lugar. la historia ha demostrado que el mercado por sí mismo no genera desarrollo y mucho menos justicia social. La economía de libre mercado no es simplemente de economías abiertas y en relación con el mercado mundial. La teoría del libre mercado considera que el mercado mundial por sí mismo asignará y desarrollará las mejores posibilidades de cada país. Para los neoliberales no hay que pensar qué país queremos y podemos ser, simplemente hay que quitar todo estorbo al mercado mundial y tendremos el mejor de los países posibles. La diferencia radical de nuestro planteo con el neoliberal no es apertura o no apertura. La diferencia es tener proyecto nacional o no tenerlo".

En anteriores artículos hemos recordado que estos movimientos de crítica y propuesta se propagan en países desarrollados, donde se plantea, en concreto, una revisión actualizada del Estado social de bienestar (ECA, 1996, pp. 865887), o se invita al despertar de las opiniones políticas porque el descontento, la inquietud y la protesta se hacen oír de nuevo. Así se expresa Alain Tourraine, Director del Instituto de Estudios Superiores de Paris: "Nadie puede desear que se ensanche el abismo que separa ya el mundo económico de los mundos político y cultural. Por tanto. es necesario hacer lo posible para que se forme una voluntad colectiva de poner fin al desarrollo sin freno del capitalismo, es decir, de la economía de mercado, mientras rechace todo control político y social de sus actividades. Hay que restablecer el control de los medios econórnicos para las finalidades políticas y sociales... La tormenta se escucha casi por todas partes, excepto en Estados Unidos, y en todos los países, incluido Estados Unidos, aumenta el temor de una crisis económica grave que incrementará la pobreza, la desigualdad y la exclusión de una manera insoportable. El largo silencio de la época neoliberal debe terminar y el debate público sobre los fines y los medios de la economía debe revivir. No perdamos más tiempo" (Realidad, 1998, p. 25).

Desde Estados Unidos, A. Schlesinger adelanta algunas predicciones constructivas sobre el próximo futuro: "El capitalismo seguirá dando bandazos, pero la ideología del laisez-faire probablemente se desvanecerá cuando los capitalistas descubran la serie de perturbaciones que el mercado sin trabas no puede resolver o incluso agravar. El capitalismo salvaje, con salarios bajos, jomada larga y trabajadores explotados, provoca el resentimiento social, resucita la guerta de clases y da nueva vida al marxismo. Para avanzar por senderos constructi- 
vos el capitalismo debe subordinar los planes y beneficios de corto plazo a necesidades sociales de largo plazo, como las inversiones en educación, investigación y desarrollo, protección del medio ambiente, ampliación de la sanidad, rehabilitación de infraestructuras y recuperación de las ciudades. No es probable que los capitalistas lo hagan por sí mismos. Las perspectivas de largo plazo exigen una direción política" (Ibidem, p. 31).

Este artículo pretende ser una colaboración al movimiento continental de crítica y propuesta frente al neoliberalismo imperante, que amenaza la identidad nacional y a los mismos gobiernos que le abren las puertas. La estrategia de convencimiento es difícil porque, en la situación actual, los grandes enemigos del Estado parecen ser los gobiernos imbuidos en esta lógica liberal. Y, por otro lado, los mismos gobiernos deben ser quienes impulsen los planes y proyectos de nación, movidos a su vez por los grupos nacionales más excluidos por las leyes del mercado: los grupos laborales, las micros-pequeñas empresas, buena parte de los empresarios productivos y de una manera general los valores, las virtudes y las tradiciones nacionales. Este eco se escucha en los cuatro mundos, y Bases para un plan de nación puede servir a este fin. Se trala de un mediano plazo y ojalá que el próximo gobierno esté abierto a este desafío continental. 